\title{
Information literacy and digital competence of teachers in the age of digital transformation
}

\author{
Konstantin Zakharov ${ }^{*}$, Aleksandra Komarova, Tatiana Baranova, and Elena Gulk \\ Peter the Great St. Petersburg Polytechnic University, 195251, St. Petersburg, Russia
}

\begin{abstract}
The study discusses the specifics of digital literacy and digital competence of a big community of teachers in one of the regions of St. Petersburg. It contains the calculations of digital literacy indices and digital competency index of the teachers that were made using the range of diagnostic tools of NAFI research center. It was found that today teachers are most advanced in content and assessment, while digital resource technology and management is the least developed field of pedagogical activity where digital technologies are applied. Two levels of digital transformation are introduced in the teaching and learning process replacement and improvement, to ensure that the zone of traditional teaching is operative. For teachers to be able to transfer successfully to the zone of pedagogical engineering, programs have to be developed to provide psychological and pedagogical support as they improve their ICT competence.
\end{abstract}

\section{Introduction}

The history of pedagogy can not boast of many discoveries that transformed the approach to teaching younger generation in a cardinal way. However, some can bementioned. The first one is the appearance of the teacher, a person who helped a boy or a girl to learn about the culture of his or her society and become its competent member. The second is the appearance of a written language. That is when literacy was mentioned for the first time. The primary task of a teacher is to teach the learner how to read and write. The third invention is book-printing and mass spread of books that contributed to the cultural, scientific and technological revolution. In the 16-17 th century Europe saw the fourth invention - a subject-classroom-lesson system of education, which quickly became traditional and has not lost its significance to this day. Finally, today we all witness the appearance of the fifth invention - the birth of the Internet, digital environment, which leads to rapid digital transformation of society and, among other things, affects education. We understand digital transformation in education as an update of all the structuralfunctional components of pedagogical systems for improving the learning outcomes of every learner (Uvarov A.) [1].Following Choshanov M. [2], Uvarov A., Frumin I. [1], digital transformation in education can be represented in the following diagram showing the change levels of pedagogy (see Fig.1).

\footnotetext{
* Corresponding author: sladogor@gmail.com
} 


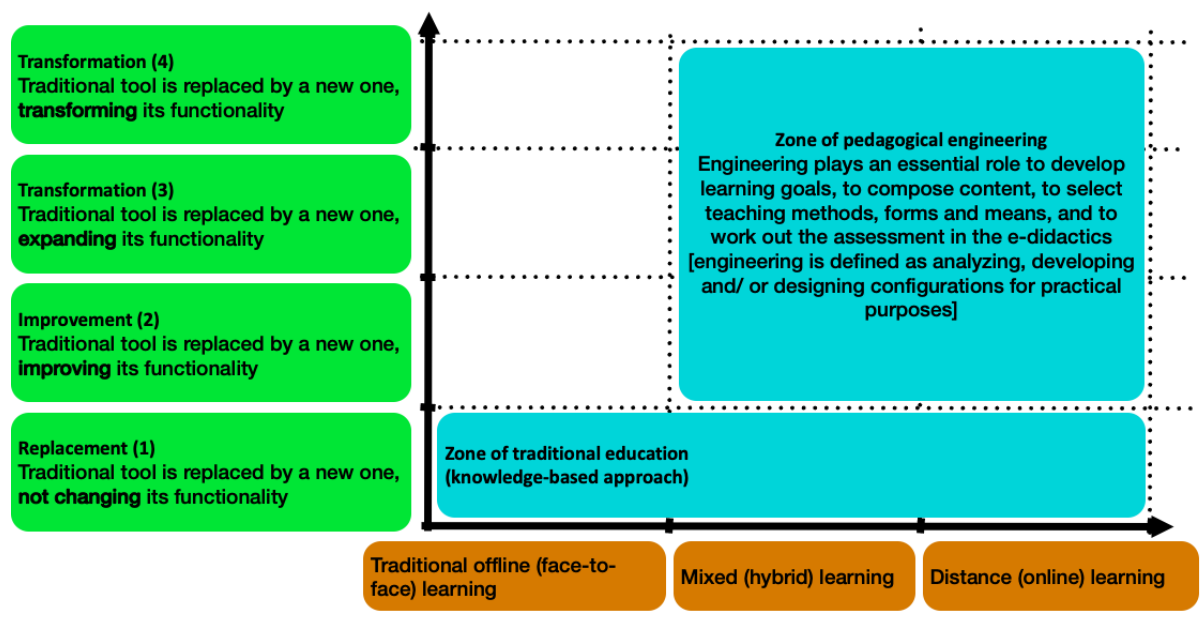

Fig. 1. Four change levels of pedagogy thanks to digital transformation.

The ordinate is the level of digital transformation in the educational process, which is known in English as the SAMR model (The Substitution Augmentation Modification Redefinition Model, Puentedura, R.) [3], and the abscissa is the learning format from traditional offline learning (face to face) through hybrid, blended learning to online distance learning. It is seen from the Figure that the zone of traditional teaching occurs at the substitution level, while entering the zone of pedagogical engineering, the zone of electronic didactics (e-didactics) [4] requires that the teacher should have new digital competencies that will allow him or her not only to improve, but also change and transform digital educational environment.

The situation is getting even more complicated because society has been experiencing systemic changes, which affect the education system among other things. In the middle of the previous century, change in technology matched the change of generations and has been accelerating ever since. It is believed that today technologies change every 5 to 7 years, while generations change every 25. This phenomenon is called the law of time. The education system has faced a challenge. It has to teach the younger generation how to learn, acquire knowledge by themselves, quickly adapt to changes, deal with uncertainty, be capable of multitask, which means that the teaching goal is changing. The world community responds to this challenge with some UN documents [5], and in the Incheon Declaration for the implementation of Sustainable Development Goal 4, UNESCO explicitly declares the promotion of lifelong learning opportunities for everyone [6].

The ordinate is the level of digital transformation in the educational process, which is known in English as the SAMR model (The Substitution Augmentation Modification Redefinition Model, Puentedura, R.) [3], and the abscissa is the learning format from traditional offline learning (face to face) through hybrid, blended learning to online distance learning. It is seen from the Figure that the zone of traditional teaching occurs at the substitution level, while entering the zone of pedagogical engineering, the zone of electronic didactics (e-didactics) [4] requires that the teacher should have new digital competencies that will allow him or her not only to improve, but also change and transform digital educational environment.

The question is whether teachers, whose job is to prepare students for a successful life in this rapidly changing world, are ready for these challenges? The teachers of the older generation remember the time when there were no computers or the Internet, while those who graduate from school today cannot imagine their life without being able to access social media on their phone. 
Researchers should ask themselves a question: do digital literacy and digital competence of teachers correspond to the level of digital literacy and digital competence of students? This hypothesis has already been tested and it turned out that tteachers' competence not only corresponds to that of their students, but they are ahead of them. The studies were carried out by a group of scientists including G.U. Soldatova [7] and experts from the NAFI research center, such as T.A. Aimaletdinov, L.R. Baimuratova, O.A. Zaitseva, G.R. Imaeva, L.V. Spiridonov [8]. Their conclusions gave us an idea to study digital literacy and competence of teachers in one of St. Petersburg's districts.

The term "digital literacy" was used by P. Gilster as early as in 1997 and has been undergoing changes since then. Basically, it is about the ability to perceive information from various Internet sources. But recently, the emphasis in defining digital literacy has shifted to the cognitive skills of an individual. It is the person who should be in the center of attention of researchers [9]. Consequently, today multidimensional approachesto the concept of "digital literacy" have been adopted and presented in the work by M. Kevman [10].

In Russia, digital literacy and competence of teachers and educators was researched by G.U. Soldatova (Moscow State University) [11], and S.G. Davydov (HSE). A.V. Sharikov proposed a "four-component digital literacy model", according to which the digital literacy index can be measured [12].

To measure "digital literacy" this concept has to be operationalized, i.e. scalesand a diagnostic methodology have to be developed. The attempts to do so were first made in 2005-2006 within the DigEuLit project [13], then in 2011 [14], and later the approach was improved by a group of experts at the G20 Summit held in Berlin in April 2017 [15]. The NAFI research center took it to develop a diagnostic tool for determining digital literacy and competence index, which we used [8]. Thus, teachers' digital literacy index is a generalized indicator showing the level of teachers' readiness for digital economy and based on the assessment of five indicators of information, computer, communication and media literacy, as well as on the attitude to technological innovation.

Digital transformation of the entire society finds it way in education setting new requirements for teachers on the part of the administration of educational institutions, parents, and students. Both positive and negative tendencies of this process should beconsidered [16]. Since 2015, the digital literacy index (DIC) has been measured at the government level by the regional public organization called "Center for Internet Technologies!" (ROCIT) together with the All-Russian Center for the Study of Public Opinion (FCIOM) [17].

\section{Methodology and Methods}

The study, conducted by the authors in September - December 2020, used the approach of the NAFI research center. To calculate the ICT Competence Index, which measures the readiness of teachers to actively use ICT in the educational process, the European Digital Competence Framework of Educators (DigCompEdu) was used. It details 22 competencies, grouped into six blocks including Professional Engagement, Digital Resources, Teaching and Learning, Assessment, Empowering Learners, Facilitating Learners' digital competence [18]. Competencies correspond to six levels of experience: Newcomer, Explorer, Integrator, Expert, Leader, and Pioneer.

The goal is to study the digital competence of teachers in secondary schools. The tasks are to assess the general level of digital competence of teachers in secondary schools; identify social factors that contribute to digital competence of teachers working in educational organizations. 
The sample consisted of 365 teachers working in secondary schools of St. Petersburg, Russia.

The sample included the following number of teachers by age groups: 100 people aged from 23 to 34 years old, 114 people from 35 to 49 years old, 141 people aged 50 to 64 years old and 10 people over 65 years old.

349 women and 16 men took part in the study.

115 people are teachers at primary schools, 234 people work in secondary schools, 16 people work with all categories of students.

As for the years of teaching experience, the numerical distribution was approximately the same, with the exception of the largest group whose work experience exceeded 30 years (89 people).

As for the experience in using digital technologies, the following groups were the most numerous: $3-5$ years (73 people), 6-10 years (110 people) and 11-15 years (74 people), the rest being approximately equal.

238 teachers received advanced training, 127 teachers did not.

The largest group of teachers include those who teach the subjects of the humanitarian cycle (114 people), the groups of teachers who teach other subjects are more or less equal in number.

Methodological tools. The survey methods included a biographical questionnaire and the questionnaire "ICT Competence of Teachers", created by the NAFI Analytical Center for the Russian educational system on the basis of the European Digital Competence Framework 2.0, 2018. These were presented for filling to the respondents in a Google form.

The methods of mathematical and statistical data processing included determining differences: the Mann-Whitney U test, the Kruskal-Wallis test, and Pearson's chi-squared test.

The empirical data were processed using the SPSS software. Statistics. Version 23.

\section{Results}

The digital competence assessment showed that teachers in general education schools have an average level of ICT competence equal to 44 out of 88 points $(50 \%)$. At the same time, there is a differentiation in terms of the qualitative content of the acquired experience (see Fig. 2). The results obtained showed that $48.54 \%$ of teachers belong to the "Integrator" group, $26.3 \%$ to the "Expert" group, 16.9\% to the "Explorer" group, 5.0\% to the "Leader" group, $3.2 \%$ to the "Newcomer" group. No teacher is experienced enough to be in the "Pioneer" group.

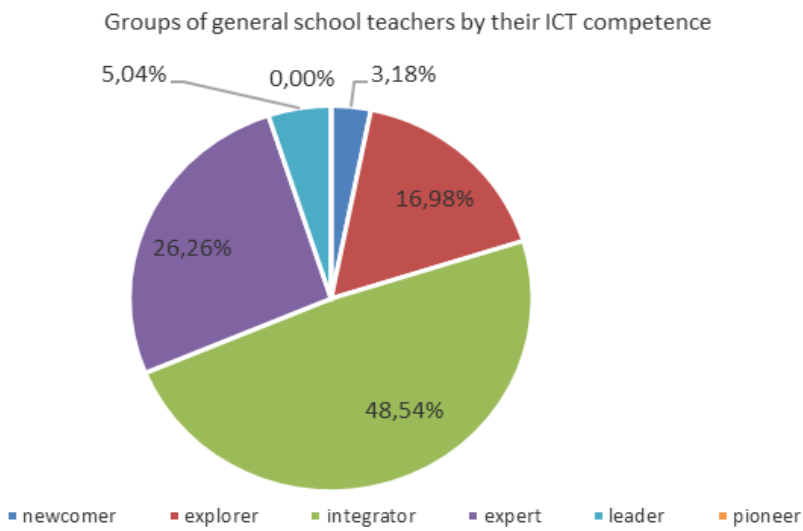

Fig. 2. Distribution of teachers by groups according to the level of ICT competence. 
It was also found that the teachers' willingness to use ICT to deal with professional problems is different depending on the type of tasks (see Fig. 3).

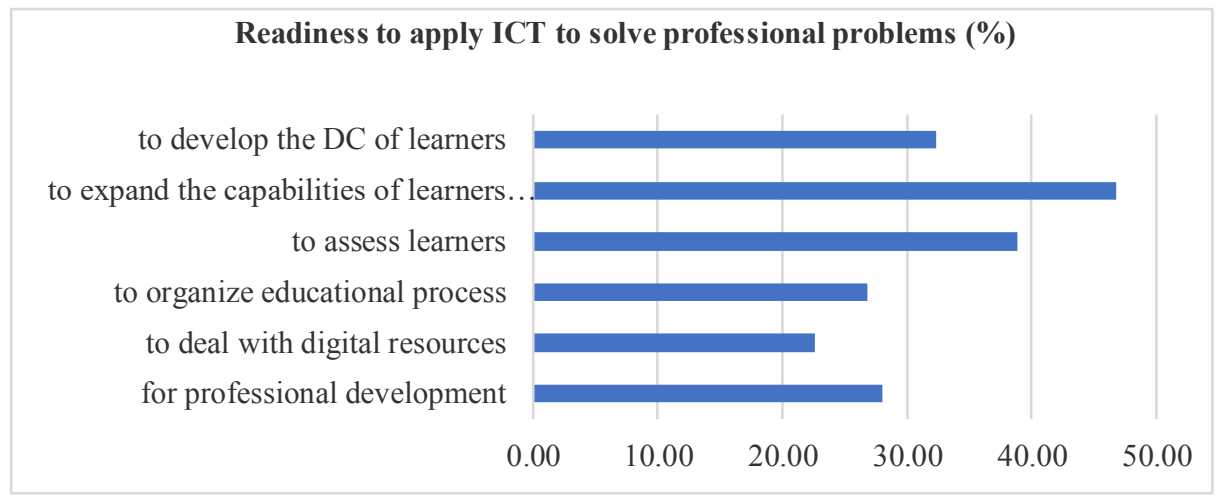

Fig. 3. The degree to which teachers working in general educational organizations are ready to use ICT to solve professional problems.

The respondents' willingness to use ICT so as to empower students to be independent in the educational process took the first place (noted by $46.8 \%$ of the teachers). In the second place $(38.6 \%)$ teachers indicated their readiness to use ICT for student assessment, the third place $(32.3 \%)$ was about the wish to develop students' digital literacy, in the fourth place $(26.9 \%)$ was the organizing of the educational process, the fifth cause $(28.1 \%)$ was for the teachers' own professional development.

In the last place (indicated by $22.6 \%$ of the teachers) was their willingness to work with digital resources in order to create, adapt, manage digital resources, etc.

To identify the factors that determine the level of digital competence of the teachers, the sample was differentiated by age, gender, work experience, experience in using ICT, students' age category, and participation in advanced training programs. What is more, the secondary school teachers were divided into groups depending on the subject they taught.

The following results were obtained:

1. The ICT Competence Index depends on their age (the general Kruskal-Wallis criterion at $\mathrm{p}=0.03)$. Teachers with the highest ICT Competence Index (53.8\%) are aged 35 to 49. Pair wise comparison of different age groups showed that the teachers of this age group are ahead of the teachers from other groups (the group aged under 35 (significance level $\mathrm{p}=0.004$ ) and the group aged 50-65 (significance level $\mathrm{p}=0.026)$ ).

2. There were no differences in the ICT Competence Index between female and male teachers (Mann-Whitney test at $p=0.431$ ). The conclusion made suggests just a trend, because the samples are not equal in terms of composition (349 female teachers and 16 male teachers).

3. Teacher shaving dissimilar each in experience do not differ in terms of the digital competence index (Kruskal-Walliscriterion $=8.891(\mathrm{p}=0.261)$, and interms of the levels of experience in using digital technologies (Pearson'schi-squared test $=35.46($ atp $=0.157)$ ).

4. The teachers' levels of proficiency in digital technologies and the general ICT Competence Index are predetermined by their experience in using ICT (Pearson's chisquared test $=107.2($ at $p=0.0001)$ ). The highest indicator of the ICT Competence Indexis in the group of teachers who have been using digital technologies for 16 years or more. Of all the teachers in this group, $20.9 \%$ are at the "Leader" level, $27.9 \%$ are at the "Expert" level, $46.5 \%$ are at the "Integrator" level. 
5. It was found that the teachers who work with different categories of students are at different levels of mastering digital technology (Pearson's chi squared test $=18.59$ (at $\mathrm{p}=$ 0.017). The ICT Competency Index is higher for those teachers who teach adolescents (Kruskal - Wallis test $=20.12(\mathrm{p}=0.001))$ The teachers working in primary schools are distributed by their level of proficiency in digital technologies as follows: "Integrator" (56.5\%), "Explorer" (21.7\%), "Expert" (15.7\%), "Newcomer" (4.3\%) and "Leader" (1.8\%). Secondary school teachers have the following distribution of the level of ICT competence: "Integrator" (45.7\%), "Expert" (30.8\%), "Explorer" (15\%), "Leader" (6.8\%), "Newcomer" $(1.7 \%)$ (see Fig. 4). As noted above, the "Pioneer" group is not represented in this sample at all.

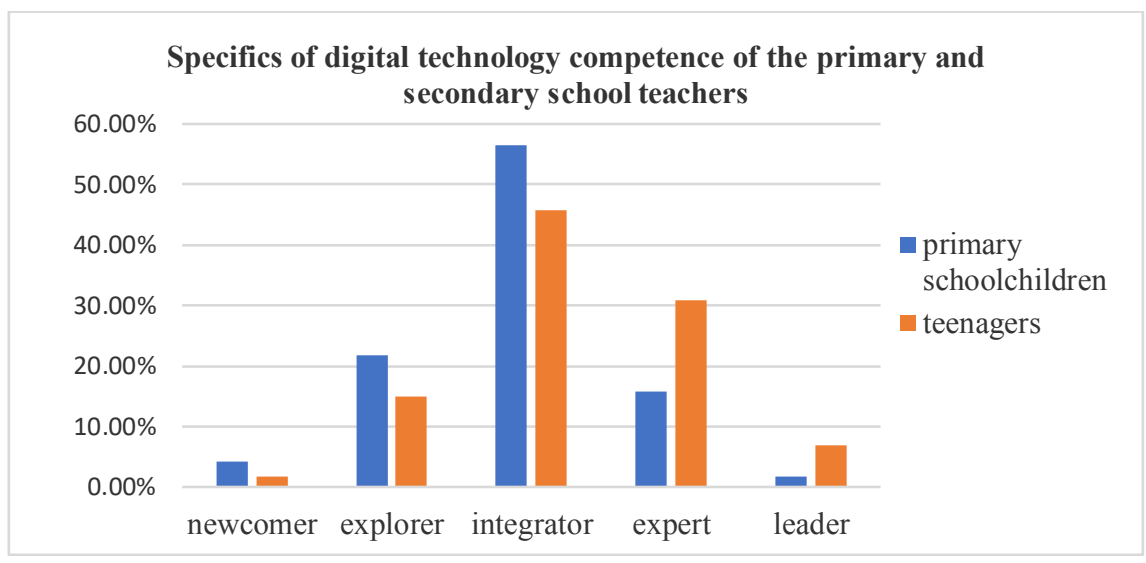

Fig. 4. Groups of primary and secondary school teachers by their level of digital competence.

6. The ICT Competence Index is higher (at a reliably significant level, established using the U-Mann-Whitney criterion $(\mathrm{p}=0.021)$ ) among the teachers who have been improving their qualifications in the field of digital technologies over the past 2 years.

7.It was found that the general digital competence index of the teachers teaching various subjects does not differ(the general Kruskal-Walliss criterion $=3.19$ at $\mathrm{p}=0.538$ ). Nevertheless, a significant difference was identified in the distribution of subject teachers by groups depending on their level of experience in digital technologies (Pearson's chi squared test $=33.93($ at $\mathrm{p}=0.006))($ see Fig.5).

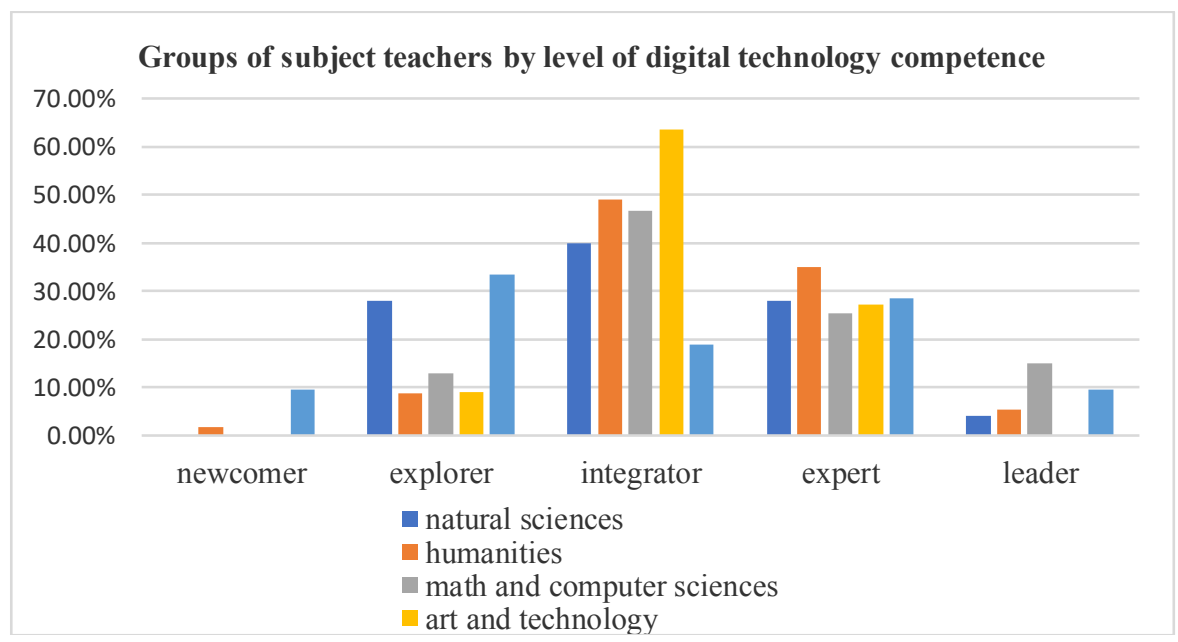

Fig. 5. Groups of subject teachers by their level of competence in digital technologies. 
The math and computer science teachers have the greatest experience and a high level of readiness to apply digital technologies $(14.9 \%$ of teachers are at the "Leader" level, $25.5 \%$ are at the "Expert" level, $46.8 \%$ are Integrators, $12.8 \%$ are Explorers). The second place in using ICT is occupied by the teachers of the humanitarian cycle of disciplines. Their digital experience is mostly associated with the functions of an Integrator $(49.1 \%)$ and an Expert (35.1\%). The data on the teachers of the natural science cycle correspond to the laws of normal distribution (the predominant function is "Integrator" (40\%), "Explorer" and "Expert" take up 28\% each, "Leader" is 4\%, "Newcomer" is $0 \%$ ), which gives us an idea of the typicality of the results obtained for the group of subject teachers being considered.

Art and technology teachers are represented mainly by two levels of ICT competence: "Integrator" (63.6\%) and "Expert" (27.3\%), with the dominating function of searching for opportunities when digital technologies are used by the teachers in their own pedagogical practice.

The group of teachers who teach physical education and the basics of health and safety $(H \& S)$ turned out to be heterogeneous in their experience in mastering digital technologies. In this group, the teachers are differentiated as those with a low level of ICT competence ("Newcomers" - 9.5\% and "Explorers" - 33.3\%) and with a relatively high level ("Experts" amount for $28.6 \%$ and "Leaders" amount for 9.5\%). To identify the causes of differentiation, further research is neededto find out how effective psychological and pedagogical support can be provided to the teachers in this group.

\section{Discussion}

The results obtained in the study are consistent with the data obtained by T.A. Aimaletdinov, L.R. Baimuratova, O.A. Zaitseva, G.R. Imaeva, L.V. Spiridonovandothers, butal so have a number of specific features associated, as we think, with the period of the study, when digital technologies have been used massive lyand there has been as harp increase in getting this experience.

The teachers are mostly ready to use digital technologies to solve the following problems: to expand the degree of students' independence in the educational process, to monitor and assess students. Much less readiness has been demonstrated by the teachers to use digital technologies to resolve the problems of students' development and their own development. The greatest difficulty is caused by the problems associated with the use of digital resources, i.e., their adaptation, creation, management, etc.

About half of the teachers $(46.8 \%)$ are ready to integrate digital technologies into the educational process. This figure is higher than in the studies conducted by other authors, which is due to the experience that the teachers gained when they organized distance education during the pandemic. In addition, according to this study the number of teachers having an expert level of ICT competence is significantly lower $(26.26 \%)$, which is caused by the lack of demand for a wide range of digital technologies in the educational institutions and the limited number of problems to be solved. The level of a "leader teacher" in the field of digital technologies is extremely low and there no innovation level has been registered.

Since the results obtained correlate with the SAMR model presented above, we can conclude about the first two levels of digital transformation implemented in the educational process, such as "substitution" and "improvement". These two levels ensure that the zone of traditional education will keep on functioning and only prepare us for the transition to the zone of pedagogical engineering. 
Since the sample of the teachers was not homogeneous, we identified some factors that affect the levels of teachers' readiness to use digital technologies and be involved in pedagogical engineering as a whole. These factors include the teachers' age, their experience in using ICT, the educational tier they work with, the specifics and needs of the subject they teach, as well as the teachers' own advancement in the field of information technology.

We believe that a higher level of ICT competence among the teachers aged 35-49 is associated both with a higher level of professional competence in general and with the level of development of the motivational and conceptual sphere of the personality of the teachers in this age group. The study of the motivational and conceptual features of using digital technologies seems to be a promising area of psychological and pedagogical research.

It is quite predictable to say that with growing experience in working with digital technologies, digital competence grows, but at the same time if there is no connection between digital competence and pedagogical activity, the teachers develop their ICT competence outside the field of their main professional activities. In addition, the identified positive effect from taking part in advanced training courses in digital technologies indicates that pedagogical and digital practices can be combined so as to make a step towards entering the zone of pedagogical engineering.

Secondary school teachers are twice as likely as primary school teachers to demonstrate their willingness to use digital technologies in a creative, critical, and consistent manner, and there are fewer Newcomers in this field. These facts are consistent with the demand for experience in the application of digital technologies at the secondary level, and also explain the differences in the levels of ICT competence depending on the subject taught.

The math and computer science teachers are ahead of their peers who teach other subjects in terms of their experience in using digital technologies ("Explorer", "Expert" and "Leader" levels prevail) and are more prepared to apply them in a comprehensive and consistent way. The second and third places are occupied by teachers of humanities and natural sciences. The results of those teaching art and technology show that their competence in digital technologies at the intermediate level, with the "Integrator" level being prevailing. The results of physical education and L\&S teachers are ambiguous and indicate the heterogeneity of the digital competence of these subject teachers. Amore detailed study has to be carried out to consider not just groups - subjects, but rather individual subjects.

\section{Conclusions}

Teachers of general educational organizations have an average level of ICT competence. At the same time, they are more open to solving the problems of integrating digital technologies into pedagogical practice and expanding their professional experience. To a lesser extent they are ready to do it comprehensively and consistently, in particular, to train other teachers or to be involved in innovative activities using sophisticated digital technologies.

The area of pedagogical activity most involved in the use of digital technologies is the content, assessment and development area, the least involved is technology and digital resource management.

The digital competence of teachers depends on:

their age (it is higher for teachers aged 35-49);

their experience in using ICT (it is higher for teachers who have experience in using ICT for 16 years or more);

the educational level of students they work with (secondary school teachers are more prepared for creative, critical and consistent use of digital technologies); 
the specifics and requirements of the subject they teach (math and computer science teachers have a higher level of ICT competence, the average level of teachers of the humanities, natural science cycle and art and technology teachers, the group of physical education and H\&S teachers is heterogeneous in terms of digital competence);

the teachers' own efforts in the field of information technology (the ICT Competency Index is higher if the teachers have undergone advanced training over the past two years).

No relationships were found between the level of digital competence, the gender or teaching experience of the teachers working in general educational organizations, as well as the experience of teaching.

When correlating the results of the study of the teachers' ICT competence with the SMAR model, it can be noted that there are two levels of implementation of digital transformation in the educational process - "substitution" and "improvement". These two levels ensure that the zone of traditional education will keep on functioning and only prepare us for the transition to the zone of pedagogical engineering.

Further research can be dedicated to studying the teachers' motivational and conceptual readiness for digital transformation.

Also, based on the results obtained and the conclusions drawn, programs can be developed to provide psychological and pedagogical support to teachers so that they can transfer to the zone of pedagogical engineering.

\section{References}

1. A. Uvarov, Difficulties and prospects of digital transformation of education (Higher School of Economics, 2019).

2. M. Choshanov, Didactics and Engineering (BINOM. Knowledge lab. Moscow, 2011).

3. R. Puentedura, Thinking About Change in Learning and Technology, Presentation given September 25, 2012 at the 1st Global Mobile Learning Conference, Al Ain, UAE (2012).

4. G. D'Angelo, From Didactics to e-Didactics: e-Learning Paradigms, Models and Techniques (Napoli, Liguori, 2007).

5. The United Nations Organization. Transforming Our World: The 2030 Agenda for Sustainable

Development.

https://sustainabledevelopment.un.org/post2015/transformingourworld (date of retrieval 03.03.2021), (2015).

6. UNESCO Institute for Lifelong Learning. CONFINTEA VI: the six international Conference on Adult Education: final report. http://unesdoc.unesco.org/images/0018/001877/187790e.pdf (date of retrieval 03.03.2021), (2010).

7. G.U. Soldatova, T.A. Nestik, E.I. Rasskazova, E.Yu. Zotova, Digital competence of adolescents and their parents (Internet Development Fund Moscow, 2013).

8. T.A. Aimaletdinov, L.R. Baimuratova, O.A. Zaitseva, G.R. Imaeva, L.V. Spiridonova, Digital literacy of Russian teachers (NAFI Publishing House, Moscow, 2019).

9. B.S. Chan, D. Churchill, T.K. Chiu, Journal of International Education Research (HER) 13 (1), 2 (2017).

10. M.L. Kewman, P. Sohee, G.J. Bang, C. Byeong-Young, Society Media and Communication 7 (2), 37 (2019).

11. G.U. Soldatova, V.N. Shlyapnikov, Psychological science and education 20 (4), 5-18 (2015). 
12. A. Sharikov, Communications. Media. Design 3 (3), 112 (2018).

13. M. Grudziecki, DigEuLit, DigEuLit: Concepts and Tools for Digital Literacy Development", 2006.

14. C. Wilson, A. Grizzle, R. Tuazon, K. Akyempong, Cheung Chi-Kim, Media and information literacy: curriculum for teachers, UNESCO, 2011.

15. K. Chetty, L. Wenwei, J. Josie, B. Shenglin, Bridging the Digital Divide (Measuring Digital Literacy, 2017).

16. I.V. Sokolova, O.A. Mudrakova, IT penetration in society and education: modern theory and practice (Moscow, 2013).

17. Digital Literacy Index. [Electronic resource]. Moscow 2015.https://wciom.ru/fileadmin/file/reports_conferences/2015/2015-12-21rocit.pdf (date of retrieval 04.03.2021) (2015).

18. The Digital Competence Framework. [Electronic resource]. https://ec.europa.eu/jrc/en/digcomp/digital-competence-framework (date of retrieval: 04.04.2021) (2018). 